\title{
Gabapentin for complex regional pain syndrome in Machado-Joseph disease: a case report
}

\author{
Yang-Ching Lo ${ }^{*}$, Kwong-Kum Liao, Yi-Chung Lee and Bing-Wen Soong
}

\begin{abstract}
Introduction: Chronic pain is a common problem for patients with Machado-Joseph disease. Most of the chronic pain in Machado-Joseph disease has been reported to be of musculoskeletal origin, but now there seems to be different chronic pain in patients with Machado-Joseph disease.

Case presentation: A 29-year-old man (Han Chinese, Hoklo) with Machado-Joseph disease experienced severe chronic pain in both feet, cutaneous thermal change, thermal hypersensitivity, focal edema, and sweating and had a history of bone fracture. These symptoms were compatible with a diagnosis of complex regional pain syndrome. After common analgesics failed to relieve his pain, gabapentin was added and titrated to $2000 \mathrm{mg} /$ day $(500 \mathrm{mg}$ every six hours) in less than two weeks. This relieved $40 \%$ of his pain and led to significant clinical improvement.

Conclusions: The pathophysiology of complex regional pain syndrome includes peripheral and central sensitizations, the latter of which might be associated with the neurodegeneration in Machado-Joseph disease. In this report, we suggest that gabapentin could inhibit central sensitization as an adjunct for complex regional pain syndrome in patients with Machado-Joseph disease.
\end{abstract}

\section{Introduction}

Machado-Joseph disease (MJD), also called spinocerebellar ataxia type 3 , is the most common subtype of spinocerebellar ataxias worldwide and is caused by a CAG trinucleotide repeat expansion in the coding region of the MJD1 gene. The main features of MJD are ataxia and ophthalmoparesis and pyramidal, extrapyramidal, and amyotrophic signs [1]. Chronic pain is one of the most disabling symptoms of MJD. Nearly $80 \%$ of the chronic pain in MJD has been reported to be of musculoskeletal origin [2]. To the best of our knowledge, no previous case report has mentioned complex regional pain syndrome (CRPS) in patients with MJD. In the case reported here, a patient with MJD experienced symptoms of CRPS, which were relieved by gabapentin.

\section{Case presentation}

A 29-year-old man (Han Chinese, Hoklo) with a diagnosis of MJD and CAG repeat numbers of 14 and 70 in the MJD1 gene had been confined to a wheelchair for three years. He had a history of left humeral bone

\footnotetext{
* Correspondence: milanlyc@gmail.com

Department of Neurology, Taipei Veterans General Hospital, No. 201, Section 2, Shih-Pai Road, Beitou District, Taipei, Taiwan, 112
}

fracture as a result of an accidental fall one year earlier. Three months prior to his stay in the hospital, he began to have severe regional pain in his feet. His pain was spontaneous, continuing, and excruciating in the areas mentioned above. He described it as like "originating deeply from the bone" and denied any burning or lancinating sensation. Moderate hair loss, focal edema, cutaneous thermal change with hypersensitivity to cold temperatures, and intermittent sweating in both feet were observed. Yet there was no light-touch allodynia, fever, chill, or local tenderness. He could hardly do anything except moan in bed in the daytime and yell and kick almost every night.

Plain film of both feet revealed normal alignment and no bone lesions. A nerve conduction study and electromyography revealed merely mild sensorimotor polyneuropathy. Quantitative sensory testing (QST) was conducted for his severely depressed mood. During his stay in the hospital, we used the visual analogue scale (VAS) (0 for no pain and 10 for maximal pain) to measure his pain intensity [3]. Initially, his pain was minimally relieved, from 10 to 8 on the VAS, by common analgesics, including acetaminophen, diclofenac, and tramadol. On day four, gabapentin was added at a daily 
dose of $1200 \mathrm{mg}$ (400 mg every eight hours) (Figure 1). With an increasing daily dosage of gabapentin from 1200 to $2000 \mathrm{mg}$ (500 mg every six hours), his pain was gradually resolved from 8 to 4 on the VAS (Figure 1) by day 10 . The abnormal cutaneous thermal change and edema also disappeared. As his pain diminished significantly, we observed a remarkable improvement in his quality of life: he slept better, was more mobile, and had more daily activity. Finally, he could move around again by wheelchair.

\section{Discussion}

In this case, all of the clinical features of pain-such as spontaneous continuing regional pain with cutaneous thermal change, thermal hypersensitivity, focal edema, moderate hair loss as trophic change, sweating, immobility, and history of bone fracture-implied CRPS [4]. CRPS is characterized by a continuing (spontaneous or evoked) regional pain that is seemingly disproportionate in time or degree to any known trauma or lesion. In the latest proposed criteria for CRPS, regional pain is not limited to a nerve territory or dermatome, which is usually accompanied by a distal predominance of abnormal sensory, motor, sudomotor, vasomotor, and trophic changes [5]. Mechanical or thermal hypersensitivity is the hallmark of nociceptive pain compatible with CRPS $[6,7]$.

In the pathophysiology of CRPS, peripheral nerve or soft tissue injuries trigger the initial peripheral nociceptive sensitization caused by prostanoids, kinins, and cytokines. Afterwards, the calcium influx and activitydependent plasticity alter the pain transmission neurons, which undergo central sensitization and lead to a major physiological change of the autonomic, pain, and motor systems [8]. Given the small-fiber distal axonopathy that is possibly a cause of CRPS [9], QST should be managed for the evaluation of small-fiber functions with cold and heat pain thresholds [10].

To the best of our knowledge, no large clinical trials in the pharmacologic treatment for CRPS have been conducted. Most of the pharmacologic rationales for CRPS (such as topical agents, anti-epileptic drugs, tricyclic anti-depressants, and opioids) were applied by the treatment of other neuropathic pain syndromes, which are strongly related to gabapentin [11]. It has been reported that gabapentin at daily doses of 900 to 2400 mg $[12,13]$ could be considered to control CRPS, but the effects seemed to be limited. We suppose that, since the neurodegeneration in MJD is multi-systemic (involving the somatosensory cortex), gabapentin might play a role in central neuromodulation via the alpha-2-delta subunit of the voltage-gated calcium channels [14]. This successful experience suggests that the adjunctive effect of gabapentin is due to inhibition at the central sensitization.

\section{Conclusions}

Our experience offers a new option to patients with MJD and chronic pain. The exact mechanism remains to be elucidated; however, gabapentin could be considered an adjunct for the treatment of CRPS in patients with MJD.

\section{Consent}

Written informed consent was obtained from the patient for publication of this case report and any accompanying images. A copy of the written consent is available for review by the Editor-in-Chief of this journal.

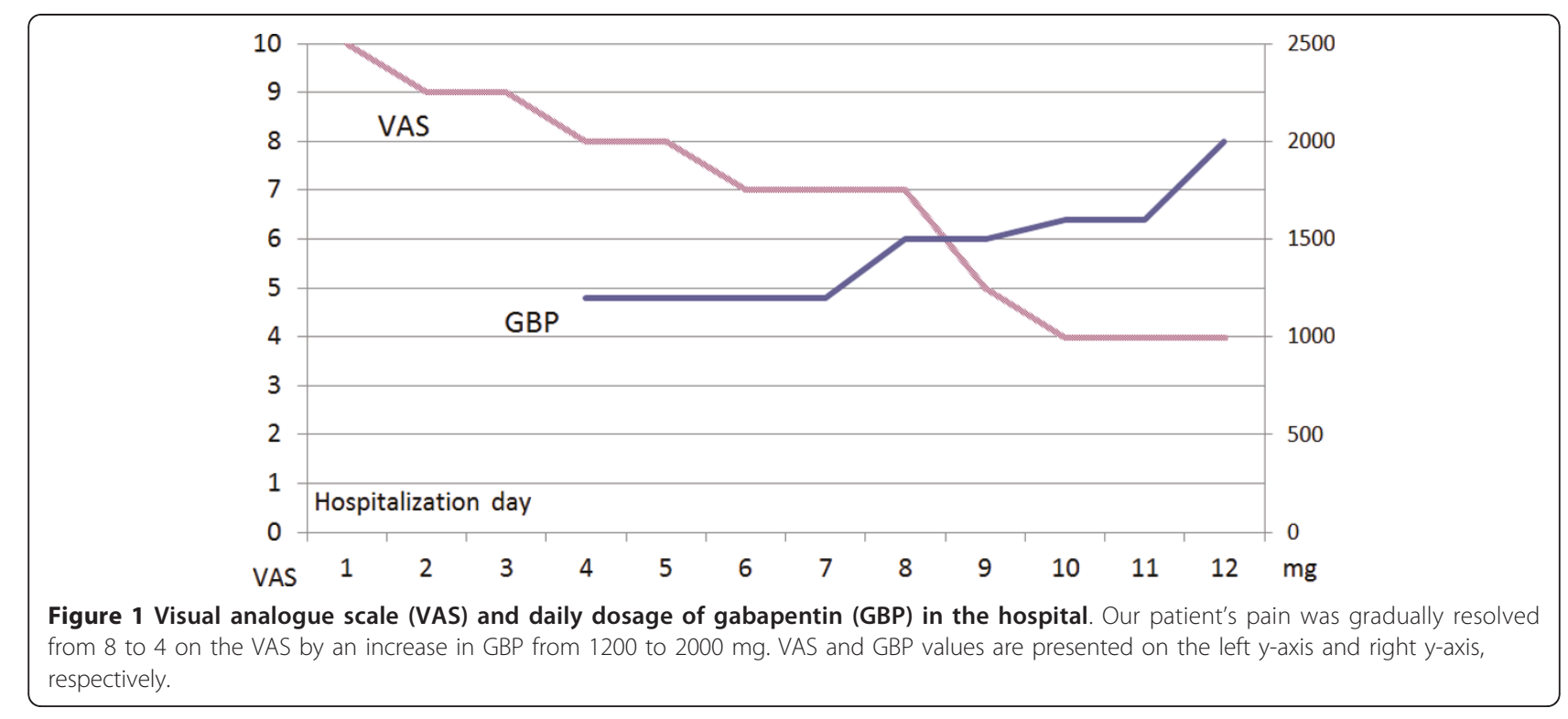




\section{Abbreviations}

CRPS: complex regional pain syndrome; MJD: Machado-Joseph disease; QST: quantitative sensory testing; VAS: visual analogue scale.

\section{Authors' contributions}

YCLo was responsible for the treatment to relieve our patient's CRPS and was a major contributor in writing the manuscript. KKL interpreted the possible pain mechanism in MJD and edited the manuscript. YCLe performed genotyping and genetic diagnosis for our patient. BWS offered the knowledge of his research in spinocerebellar ataxia. All authors read and approved the final manuscript.

\section{Competing interests}

The authors declare that they have no competing interests.

Received: 22 December 2010 Accepted: 1 July 2011

Published: 1 July 2011

\section{References}

1. Soong BW, Paulson HL: Spinocerebellar ataxias: an update. Curr Opin Neurol 2007, 20:438-446.

2. França MC Jr, D'Abreu A, Friedman JH, Nucci A, Lopes-Cendes I: Chronic pain in Machado-Joseph disease: a frequent and disabling symptom. Arch Neurol 2007, 64:1767-1770.

3. Haanpää ML, Backonja MM, Bennett MI, Bouhassira D, Cruccu G, Hansson PT, Jensen TS, Kauppila T, Rice AS, Smith BH, Treede RD, Baron R: Assessment of neuropathic pain in primary care. Am J Med 2009, 122(10 Suppl):S13-21

4. Harden RN, Bruehl S, Perez RS, Birklein F, Marinus J, Maihofner C, Lubenow T, Buvanendran A, Mackey S, Graciosa J, Mogilevski M, Ramsden C, Chont M, Vatine JJ: Validation of proposed diagnostic criteria (the "Budapest Criteria") for complex regional pain syndrome. Pain 2010, 150:268-274.

5. Harden RN: Objectification of the diagnostic criteria for CRPS. Pain Med 2010, 11:1212-1215.

6. Costigan M, Scholz J, Woolf CJ: Neuropathic pain: a maladaptive response of the nervous system to damage. Annu Rev Neurosci 2009, 32:1-32.

7. Schwartzman RJ, Erwin KL, Alexander GM: The natural history of complex regional pain syndrome. Clin J Pain 2009, 25:273-280.

8. Schwartzman RJ, Alexander GM, Grothusen J: Pathophysiology of complex regional pain syndrome. Expert Rev Neurother 2006, 6:669-681.

9. Oaklander AL, Fields HL: Is reflex sympathetic dystrophy/complex regional pain syndrome type I a small-fiber neuropathy? Ann Neurol 2009, 65:629-638.

10. Rolke R, Magerl W, Campbell KA, Schalber C, Caspari S, Birklein F, Treede RD: Quantitative sensory testing: a comprehensive protocol for clinical trials. Eur J Pain 2006, 10:77-88.

11. Rosner $H$, Rubin L, Kestenbaum A: Gabapentin adjunctive therapy in neuropathic pain states. Clin J Pain 1996, 12:56-58.

12. Mellick GA, Mellick LB: Reflex sympathetic dystrophy treated with gabapentin. Arch Phys Med Rehabil 1997, 78:98-105.

13. Tan AK, Duman I, Taşkaynatan MA, Hazneci B, Kalyon TA: The effect of gabapentin in earlier stage of reflex sympathetic dystrophy. Clin Rheumatol 2007, 26:561-565.

14. Maneuf YP, Luo ZD, Lee K: Alpha2delta and the mechanism of action of gabapentin in the treatment of pain. Semin Cell Dev Biol 2006, 17:565-570.

doi:10.1186/1752-1947-5-268

Cite this article as: Lo et al:: Gabapentin for complex regional pain syndrome in Machado-Joseph disease: a case report. Journal of Medical Case Reports 2011 5:268.

\section{Submit your next manuscript to BioMed Central and take full advantage of:}

- Convenient online submission

- Thorough peer review

- No space constraints or color figure charges

- Immediate publication on acceptance

- Inclusion in PubMed, CAS, Scopus and Google Scholar

- Research which is freely available for redistribution

Submit your manuscript at www.biomedcentral.com/submit
Biomed Central 